\title{
El fenómeno de la voluntad que quiere: una puerta a la trascendencia en Maurice Blondel
}

The Phenomenon of the Will that Wants: A Gate to Transcendence in Maurice Blondel

Carlos Andrés Gómez Rodas $\otimes$ Universidad Pontificia Bolivariana

Recibido: 14 de septiembre de 2014

Enviado a pares: 15 de septiembre de 2014

Aceptado por pares: 13 de noviembre de 2014

Aprobado: 19 de noviembre de 2014

Pensamiento y Cultura | ISSN: 0123-0999 | elSSN: 2027-5331

pensam.cult | Vol. 17-2 | Diciembre de 2014 | pp. 97-117

DOI: 10.5294/pecu.2014.17.2.5

$\diamond$ cgomezrodas@gmail.com 


\title{
El fenómeno de la voluntad que quiere: una puerta a la trascendencia en Maurice Blondel
}

Resumen: Frente a un contexto filosófico que se lo exigía, el filósofo francés Maurice Blondel (1861-1949) supo explorar las profundidades de la acción humana, partiendo del fenómeno de una voluntad que quiere (Volontévoulante) que nunca encuentra plena satisfacción en el mundo de los fenómenos. Tal "método de inmanencia", como algunos lo han llamado, comienza su marcha en las inquietudes existenciales del hombre, en la pregunta por su destino y su sentido, pero descubre en ese recorrido, la necesidad de una hipotética donación sobrenatural, pues la razón humana se encuentra limitada para dar respuesta a los deseos de la voluntad, que parecieran reclamar el infinito.

Palabras clave: voluntad que quiere, inmanencia, trascendencia, acción, metafísica, fenómeno, fe, razón.

\section{The Phenomenon of the Will that Wants: A Gate to Transcendence in Maurice Blondel}

\begin{abstract}
Facing a philosophical context, the philosopher Maurice Blondel (1861-1949) knew how to explore the depth of human action, beginning with the phenomenon of the will that wants (Volonté voulante) that never finds full satisfaction in the world of phenomenon. This "method of immanence" as some people have named it, begins in the existential concerns of the human being, in the question about his destiny and his sense, but discovers in that trail, the need of a supernatural hypothetical donation because human reason is incapable of giving an answer to the desires of the will, that seems to claim for infinity.
\end{abstract}

Keywords: Will that wants, immanence, transcendence, action, metaphysics, phenomenon, faith, reason. 
"Existe en el hombre una capacidad suprema que llenar, ¿para quién será?" Maurice Blondel. La Carta Apologética, 61

\section{Introducción}

En su Defensa de la Filosofía, el pensador alemán Josef Pieper lanzaba una crítica al racionalismo en el cual está cimentada buena parte de la filosofía moderna, e invitaba a una mirada mucho más amplia de lo que constituye la misión del filósofo:

Ahora bien, quien dijera, por ejemplo, esto que es obvio para la consideración científica: Yo dejo de lado todo lo que no se puede demostrar con toda evidencia ni verificar críticamente; solo me interesa lo que se puede conocer "clara y distintamente", este tal habría fallado ya en el planteamiento de la pregunta filosófica; habría descartado de antemano la apertura que por definición caracteriza al que filosofa, o sea la apertura con vistas al objeto íntegro, sin recortes, del conocimiento humano, que es la realidad en conjunto, la cual se ha de considerar bajo todos los aspectos posibles. En efecto, ¿cómo sabe él que no puede haber datos sobre la realidad, que en verdad son datos aunque no se puedan verificar "clara y distintamente"?(...) ¿Cómo sabe él que no es verdad lo que afirma Aristóteles, a saber, precisamente lo que en sí es solo "lo más manifiesto de todo", es precisamente aquello frente a lo cual nuestra inteligencia se comporta como el ojo de la lechuza frente a la luz del día? Proceder "críticamente" no significa primariamente para el filósofo admitir solo lo que está absolutamente asegurado, sino poner cuidado en no escamotear nada (Pieper 1970, 58).

Tal vez, una de las falacias lógicas que más le cuesta superar a quienes se dedican a la apasionante tarea del pensamiento, sea aquella que podría catalogarse como una petición de principio, consistente en afirmar que el conocimiento de la realidad es la realidad efectiva, que el universo de las cosas llega hasta donde alcanza nuestro limitado entendimiento y que aquello que supera nuestra capacidad racional es simplemente ilusorio o fantástico, olvidando que la "cognoscibilidad", 
como propiedad de los entes, no significa que la realidad sea, sin más, comprensible a nuestro espíritu, menos aún, que la especulación pueda considerarse la única vía hacia el conocimiento, ignorando el mundo afectivo y volitivo de la persona como una puerta a cuestiones que, desde lo meramente intelectual o nocional, son inaccesibles.

El contexto filosófico en el que Maurice Blondel (1863-1949) desarrolló las ideas principales de su ciencia de la acción -expuestos en su tesis doctoral de 1893, titulada La Acción - y que coincide con lo que Ortega llamó el "imperialismo de la física” (Ortega y Gasset 2007, 57), está marcado indudablemente, por las consecuencias del racionalismo antes mencionado, a saberse, el positivismo, el materialismo y el fenomenismo, ante los cuales la metafísica aparecía como un saber anacrónico, propio de un periodo ya superado por la modernidad ideológica y los avances técnico-científicos, que en la segunda mitad del siglo XIX se sucedieron unos a otros vertiginosamente, haciendo que el hombre depositara todas sus esperanzas en los conocimientos de las ciencias positivas con los cuales podía transformar el mundo.

Mientras que la reacción de muchos fue encerrarse en los guetos del neotomismo sin buscar establecer diálogo con las nuevas propuestas filosóficas - actitud que alimentó una recíproca hostilidad- Blondel encontró en la acción humana un fenómeno cuyo estudio le concedía validez frente a sus contemporáneos y, al mismo tiempo, le permitía explorar las profundidades del hombre para verificar si la renuncia radical a la metafísica estaba o no justificada. De esta manera se constituye un método de inmanencia que pretende asumir el fenomenismo como punto de partida, pero no como conclusión ontológica, ya que en la línea de Pieper, Blondel reconocía que "lo que nosotros percibimos no es la única, verdadera y total realidad de lo que percibimos realmente" (Blondel 1996, 76).

Con el método de inmanencia no se prejuzga la realidad de lo sobrenatural, pero sí se juzga y rechaza el principio o sistema de inmanencia, que consistiría en afirmar la autosuficiencia del hombre y la exclusión subjetivista de toda realidad trascendente, máxime cuando se acepta que la voluntad humana permanece insatisfecha en los límites de dicha inmanencia. ¿Podría esta reflexión sobre la voluntad aportar a una 
discusión que parecía exclusiva de la dimensión especulativa y abrir la puerta a una dimensión que parecía cerrada?

El presente artículo tiene como objetivo dar a conocer la teoría blondeliana sobre un ámbito concreto de la fenomenología de la acción: la volonté voulante o voluntad que quiere, particularmente en dos obras que se consideran fundamentales en el diálogo de Blondel con la teología: La Carta Apologética e Historia y Dogma, en cuyas páginas es posible encontrar una apertura metafísica desde los principios de la filosofía moderna.

\section{Un hallazgo en la acción: La voluntad que quiere}

El fundamento epistemológico de una ciencia de la acción se encuentra en su innegable necesidad. Tenemos que actuar, podría decirse que estamos envueltos en la acción sin haberlo querido y resulta imposible escapar de ella porque nos es inherente.

Si consulto a la evidencia inmediata, la acción es un hecho en mi vida, el más general y el más constante de todos; es la expresión en mí del determinismo universal. La acción se produce incluso sin mí. Más que un hecho, es una necesidad que ninguna doctrina niega, pues esta negación exigiría un esfuerzo supremo que todo hombre evita, ya que el suicidio sigue siendo un acto. La acción se produce incluso a mi pesar. Más que una necesidad, la acción se me muestra a menudo como una obligación (Blondel 1996, 4).

El hombre, por tanto, actúa porque quiere, pero su "querer" no puede ser interpretado como un hecho psicológico, como algo contingente de darse o no darse. A la necesidad del actuar le corresponde una necesidad en el querer, que responde a la más íntima estructura del sujeto; no puede "no querer" y en la medida que lucha contra este impulso natural de la voluntad, descubre que su combate está destinado al fracaso y que el deseo se hace cada vez más grande, expandiéndose incluso más allá de los fenómenos a su alcance. En otras palabras, para Blondel no solo es imposible anular el querer 
sino también reducirlo al ámbito de lo inmanente, de aquello que el mismo hombre produce o genera:

El inmenso orden de los fenómenos en que se expande la vida del hombre parece agotado, y, sin embargo, el querer humano no lo está. La pretensión de autosuficiencia que tiene ese querer termina fracasando (...) El hombre pretendía arreglarse en solitario y encontrar en el orden natural su suficiencia y su todo. Pero no lo consigue. No consigue ni detenerse ni pasar adelante. No puede retroceder, ya que lo mínimo que ha podido querer es ese orden natural de fenómenos, ese algo en el cual descubre simplemente no una razón para no querer, sino una imperiosa razón de querer más (Blondel 1996, 373).

Lo anterior revela un conflicto al interior de la voluntad, pues si el hombre identifica lo que quiere pero no se satisface con ello, permanece siempre inadecuado, incompleto, carente de algo que sin poder señalar ni tener referente fenoménico pareciera poder llenarlo y calmar sus ansias, tendientes siempre al infinito. Para explicar esta realidad, el filósofo de Aix acuñó los conceptos de voluntad que quiere (volonté voulante) y voluntad querida (volonté voulue) en cuya explicación no hay que precipitarse, pues se corre el riesgo de caer en confusiones y traicionar los planteamientos de la filosofía de la acción.

No es muy difícil comprender el concepto de voluntad querida cuando la cotidianidad nos descubre llenos de aspiraciones, anhelos, deseos, sueños y afanes; queremos obtener bienes, alcanzar puestos, vivir experiencias, tener la compañía de determinadas personas, y muchas veces, sumergirnos en el mar de las sensaciones por las sensaciones mismas. El Libro del Eclesiastés, en el que Salomón habla de su vida en medio de la opulencia y los placeres, presenta un buen ejemplo del hombre que lleno de gloria, honor y riquezas puede disponer a su antojo las circunstancias y gozar de unas condiciones envidiadas por cualquiera:

Me dije para mis adentros: ¡Voy a probar con el placer y a disfrutar del bienestar! Traté de regalar mi cuerpo con vino, mientras guiaba mi reflexión con sabiduría, y de entregarme a la necedad hasta ver en qué 
consistía la felicidad de los humanos, lo que hacen bajo el cielo durante los contados días de su vida. Emprendí mis grandes obras; construí palacios, planté viñas; me hice huertos y jardines, y los planté de toda clase de árboles frutales. Me construí albercas para que el agua regase la fértil fronda. Tuve siervos y esclavas: poseí servidumbre, así como ganados, vacas y ovejas, en mayor cantidad que ninguno de mis predecesores en Jerusalén. Atesoré también plata y oro, tributos de reyes y de provincias, me procuré cantores y cantoras, toda clase de lujos humanos, coperos y reposteros. Nada negué a mis ojos de cuanto me pedían, ni rehusé a mi corazón ninguna alegría (2, 1.3-8.10).

La voluntad querida puede entenderse entonces como lo fáctico, lo que efectivamente pensamos, queremos y hacemos pero que siempre es finito y limitado con respecto a la voluntad que quiere más y más. No es por otra razón que Miguel de Unamuno reclama en carta a Jiménez Indulaín: "Digo que lo que pasa no me satisface, que tengo sed de eternidad, y que sin ella me es todo igual. Yo necesito eso, jlo ne-ce-si-to! Y sin ello ni hay alegría de vivir ni la alegría de vivir quiere decir nada. Es muy cómodo esto de decir: ‘Hay que vivir, hay que contentarse con la vida!’ ¿Y los que no nos contentamos con ella?” (Unamuno 1996, 141) y que Salomón concluye al final de sus faenas: "Consideré entonces las obras de mis manos y lo mucho que me fatigué haciéndolas, y vi que todo es vanidad y atrapar vientos, y que ningún provecho se saca bajo el sol" (Eclesiastés 2,11).

Hemos querido y hemos realizado aquello que nuestra voluntad nos movía a realizar, pero seguimos queriendo; Blondel no se detiene en esta conclusión evidente, su objetivo no es demostrar los limitados alcances de la voluntad querida, sino hallar su causa, su condición de posibilidad, la estructura que le da soporte, porque para Blondel “(...) esta necesidad a posteriori resulta del movimiento a priori de la voluntad" (Blondel 1996, 325).

El plano de la "volonté voulue" lo constituye el ámbito de lo observable fácticamente, es decir, de aquellas experiencias explícitas que la vida de la acción adopta en su desarrollo expansivo natural. Un tal nivel es contemplado, sin embargo, desde el horizonte de trascendentalidad 
en el que, al modo kantiano, se sitúa Blondel. Este horizonte está representado por el nivel de lo "voulante" que constituye el plano estructural de la condición de posibilidad. De este modo, el contenido observable de la acción es escrutado desde el horizonte de la idealidad trascendental que constituye, propiamente, el conjunto de condiciones a priori que explican, fundamentan y hacen posible el desarrollo concreto y puntual de la acción (Arrieta 1993, 48-49).

La voluntad que quiere, es entonces, un "querer condición, un querer no-posicional, una voluntad necesaria" (Cartier 1955, 62), es decir, un querer que permite cualquier acción objetiva y positiva, es ilimitada en sus aspiraciones y, movida por el empuje de la vida, no reposa en lo que solo parcialmente responde al problema humano, es el esqueleto en el que se sostiene la voluntad querida y que existe en nosotros sin haberlo pedido, pues si bien es cierto que puedo obtener lo querido, yo no he pedido ni he querido querer (cfr. Blondel 1996, 374):

En la historia natural de la acción, siempre ha sido posible eliminar la variable para considerar sólo el carácter común y la característica esencial de cualquier desarrollo de la actividad humana (...) Bajo las formas contingentes y arbitrarias de la vida, siempre hay una cadena necesaria y una especie como de esqueleto rígido sobre el que se apoyan los movimientos más flexibles y variados (Blondel 1996, 524).

A primera vista, se podría pensar que se habla de dos géneros de voluntades, pero en realidad no se trata de esto. Hay una única voluntad en conflicto, como antes se señaló, y las categorías de voluntad querida y voluntad que quiere no solo pretenden mostrar una relación entre lo dado y su condición, entre el efecto y la causa, sino que también son usadas por el filósofo francés para hacer comprensible esta inadecuación permanente que tiende a la solución y en la cual tiene su origen el dinamismo dialéctico de la acción.

Dado que dicha solución no se encuentra en el orden natural, Blondel afirma la apertura del hombre a una respuesta sobrenatural. Con esto no pretendía demostrar la existencia de lo trascendente, sino 
sustentar el carácter científico de la afirmación de que la subjetividad reclama algo más allá de lo natural y el hombre está constitutivamente abierto al infinito (cfr. Valdés 2008, 23).

Podría decirse, por citar un ejemplo, que para el filósofo de Aix, el puente entre la filosofía y la teología se sostiene en los pilares de esta apertura a lo sobrenatural y en la aproximación a la voluntad que quiere como un hecho indiscutible de la inmanencia-el hombre lo descubre en su interior como necesario, como parte suya-que lleva la fenomenología de la acción más allá de lo inmanente. Por esta razón resulta valioso explorar el papel de este concepto en el diálogo que tuvo el pensador francés con teólogos y apologistas cristianos, expuesto en las dos obras que se abordarán a continuación.

\section{La voluntad que quiere en la Carta Apologética}

La obra de Blondel fue objeto de duras críticas por parte de filósofos no cristianos, aunque también algunos neoescolásticos se mostraron reacios a sus propuestas, por juzgarlas contrarias a la fe. En el primer grupo, muchos consideraban que la tesis sobre la acción era más propia de un teólogo y que recaía en posturas de corte religioso inaceptables para la época, además, algunos no comprendían (y quizá nunca comprendieron) cómo era posible estudiar la acción y no la idea de acción, en lo cual el filósofo de Aix siempre insistió.

Para no faltar a la verdad histórica y buscando matizar lo dicho anteriormente, es importante añadir que dentro del ambiente intelectual católico de su época la filosofía blondeliana de la acción fue recibida de modos diversos. Algunos teólogos la consideraron incompatible con la doctrina católica y sus dogmas mientras que otros la acogieron con entusiasmo y la elogiaron notablemente, incluso cuando no la interpretaran del todo acertadamente. En este segundo grupo sobresale el P. Charles Denis, que pese a su intención de alabar La Acción y reconocer su valor, le daba una lectura de corte psicológico, según la cual el cristianismo quedaría afirmado y demostrado por su conformidad con las necesidades del pensamiento o su adaptación a las necesidades de la vida, lo cual reducía al filósofo de Aix a un apologista filosófico del cristianismo. 
Ante este hecho Blondel intervino para aclarar cuál era realmente la propuesta de La Acción y cómo debían aproximarse a ella filósofos y teólogos. Así, en una primera carta que se publicó en los Anales de Filosofía Cristiana, Blondel insistió que no era ni se entendía como un apologista, sino como un filósofo, indicando al mismo tiempo que no se podía confundir una apologética filosófica que busca defender la fe por medio de argumentos racionales con una filosofía apologética cuyos intereses son genuinamente filosóficos y se aproxima críticamente a la fe con un método científico, a esto el francés añadía que la segunda no podía nunca tornarse en una forma más de la primera (cfr. Valdés 2008, 92).

Con el objetivo de mostrarle a los filósofos modernos que su exigencia de un punto de partida inmanente estaba satisfecha en la filosofía de la acción, se publicó por entregas en los Anales de Filosofía Cristiana entre enero y julio de 1896 un artículo titulado "Carta sobre las exigencias del pensamiento contemporáneo en materia de apologética y sobre el método de la filosofía en el estudio del problema religioso" que se ha llamado generalmente Carta apologética.

Uno de los principales problemas que Blondel encontraba en la apologética tradicional consistía en seguir insistiendo en la validez racional de la creencia, pretendiendo que por un sistema muy bien construido de argumentos, el incrédulo, tarde o temprano, daría el paso hacia la fe. Desde su particular perspectiva, la cuestión apologética no se reducía simplemente a una pugna académica en la que triunfaba quien pudiera responder de modo más consistente a los cuestionamientos del interlocutor. La importancia de la voluntad humana sobresale también en esta obra, pues nadie cree si no encuentra la necesidad de creer o si en hacerlo descubre una amenaza más que un bien para su forma de vida: "No nos cansamos de repetir argumentos conocidos, de ofrecer un objeto, mientras que es el sujeto quien no está dispuesto" (Blondel 1991, 39).

En sus Cantos de Maldoror, el Conde de Lautréamont expresaba de modo conmovedor su sed de trascendencia: "Yo, igual que los perros, siento la necesidad del infinito (...) ¡Pero no puedo, no puedo satisfacer esa necesidad!" (Lautréamont 1988, 65). Pieter Van der Meer citaba ya hace unas décadas esta frase pronunciada por "un desesperado que no conoce a Dios, que ha rechazado a Dios, y no sabe ya a qué atenerse ni 
dónde asirse" (Van der Meer 1954, 7) y es que llama mucho la atención ese detalle, que quien grita con impresionante elocuencia su necesidad no conozca la divinidad ni se haya interesado mucho por ahondar en una doctrina religiosa. Acudir a este ejemplo permite comprobar lo que la Carta Apologética sugiere en sus páginas, esto es, que las disposiciones de ánimo en el sujeto no son un asunto secundario cuando se trata de discusiones sobre la fe, e incluso, proponer que son importantes tampoco sería una afirmación fiel a la realidad, más bien, lo correcto es decir con Blondel que "este papel de preparación subjetiva es de primera importancia" (Blondel 1991, 39) y que antecede a cualquier otro aspecto del problema, más aún:"Para que el hecho pueda ser acogido por nuestro espíritu e incluso impuesto a nuestra razón, es menester que una necesidad íntima y un apetito imperioso nos preparen a ello" (ibídem, 30).

Llegados a este punto, habría que señalar que si la filosofía hace mal en precipitarse a afirmar la realidad de lo sobrenatural, lo hace también cuando ignora la "necesidad íntima" y el "apetito imperioso" a los que se refiere Blondel. Por sí misma no puede responder a la voluntad que quiere, pero racionalizar su tendencia al infinito, cayendo en el naturalismo, sería llegar a conclusiones que no le corresponden y que en modo alguno puede explicar.

Es preciso mostrar la necesidad para nosotros de adherirnos a esta realidad de lo sobrenatural (...) Por tanto desde el momento en que la filosofía no debe revestir también lo sobrenatural del género de certeza que confiere a todo lo que afirma, no tiene por qué pronunciarse sobre la cuestión de hecho. Su única misión es la de determinar las disposiciones de ánimo que preparan la inteligencia de los hechos y el discernimiento práctico de las verdades propuestas por otra parte (Blondel 1991, 28-29).

Durante la Modernidad, las relaciones entre la fe y la razón empeoraron paulatinamente y no se puede ocultar que buena parte de los intentos por conciliarlas fueron traiciones disimuladas a alguna de las partes en conflicto. Fue así como se cayó en el racionalismo teológico, de importantes consecuencias en el plano de la exégesis bíblica hasta hoy, pues los teólogos trataron de justificar la creencia ante los ojos de 
los filósofos dando una explicación sobre los hechos de la fe que resultara creíble o adecuada a los límites de la razón humana, pues buena parte de ellos habían sido distorsionados por las primeras comunidades cristianas, que permanecían todavía en un periodo mítico del pensamiento. De este modo, la fe, los dogmas y la Revelación aparecían como una poética de lo inmanente sin relación alguna con la realidad, que se encontraba limitada en el orden natural.

Para Blondel, no es mediante tal confusión de planos y usurpación recíproca de disciplinas que se logra resolver el conflicto, más bien se hace necesario que la filosofía sea rigurosamente filosofía y

que la teología sea lo que ella es; todo y sólo lo que es. Que los teólogos y todos los que tienen misión y gracia para difundir la ciencia sagrada permanezcan enteramente teólogos, sin creer que han de sacar ventaja alguna en velar o complicar su carácter, en humanizar su enseñanza, en perder el acento de su autoridad, en referir todo a los argumentos filosóficos, en hablarnos principal o únicamente de lo que quizá conocemos mejor que ellos cuando esperamos que nos hablen de lo que sólo ellos pueden darnos (...) Ya que, en realidad, no tienen que tomar ni la ofensiva ni la defensiva sino hacer lucir el sol sobre los buenos y los malos, desarrollando ante nuestros ojos el sistema racional de la fe (Blondel 1991, 73-74).

La Carta Apologética tiene como objetivo mostrar el punto de acuerdo que hay en medio del conflicto entre la filosofía y la religión, entre lo inmanente y lo sobrenatural. Tal parece que es la voluntad que quiere como fenómeno la que permite encontrar ese acuerdo, esa conexión que enlazaría dos dimensiones aparentemente condenadas a la separación y la mutua hostilidad (cfr. Blondel 1996, 143-44) pues ella es un inmanente trascendente, inmanente como necesidad y trascendente a nuestras naturales posibilidades de satisfacerla, natural en cuanto al deseo o apetito, pero sobrenatural en cuanto a la consecución.

En efecto, que lo sobrenatural para existir sea humanamente inaccesible es lo que enseña la fe y exige la razón. Lo que la primera nos impone como real, la segunda lo concibe como necesario a la vez que 
impracticable para nosotros. La una declara como gratuitamente dado lo que la otra no puede menos de postular invenciblemente. Coinciden, pues, en que no desarrollan nunca más una doble misión, y también en que la una está vacía donde la otra está llena (Blondel 1990, 49).

En la necesidad de lo sobrenatural fundamenta Blondel una nueva apologética, que hunde sus raíces en la filosofía de la acción. "Lo sobrenatural no es fundado filosóficamente, sino que la filosofía permite que lo sobrenatural 'aparezca' como epistemológicamente necesario ante el sujeto" (Valdés 2008,99 ). Se ha visto ya que si no se cuenta con la inadecuación de la voluntad, si el hombre aún no sintoniza con ese deseo superior y se encuentra satisfecho en medio de los fenómenos, la exposición de la fe le resultará a lo sumo, tan interesante como un discurso sobre una materia incomprensible y que nada tiene que ver con la vida práctica a la que se enfrenta diariamente. La apologética comenzará a dar fruto cuando quien habla haya tenido esa experiencia de vacío y cuando quien escucha halle en lo más profundo de su ser una insaciable voluntad que quiere, para la cual mil nadas no forman una cosa, mil gozos no dan la felicidad, mil sensaciones no aquietan el alma, mil deseos concedidos no apagan el querer (cfr. Blondel 1996, 375). Así pues, la vivencia religiosa "No se trata, en efecto, de una adhesión teórica del espíritu a un dogma exterior a nosotros, sino de la admisión práctica de una verdad vivificante dentro de nuestro corazón y en nuestra conducta" (Blondel 1991, 79).

\section{La voluntad que quiere en Historia y Dogma}

Las relaciones entre historia y fe en el marco de la crisis modernista interesaron profundamente a Blondel. Su diálogo continuo con el teólogo Alfred Loisy y otros autores representativos de ese contexto, llevó a que la oposición al filósofo de Aix se formulara como una acusación de connivencia con las ideas modernistas en el plano de la exégesis bíblica. Ciertamente esta relación es innegable, pero, a diferencia de quienes acabarían protagonizando los episodios más destacados de la crisis, Blondel mantuvo siempre una actitud de concordia y respeto por la ortodoxia católica (cfr. Izquierdo 1999, 923). 
Después de que Loisy publicara El Evangelio y la Iglesia en 1902, comenzó una correspondencia entre el exégeta y el filósofo que le permitió descubrir a este segundo, planteamientos e ideas muy afines con su propia visión de las cosas, pero al mismo tiempo, pudo notar una propuesta sobre las relaciones entre historia y fe, entre la vida real del hombre y el dogma católico que le resultó inquietante. Todo ello fue preparando la publicación, en 1904, de los tres artículos que constituyen Historia y Dogma (cfr. Izquierdo 1999, 924).

Loisy se ceñía al método histórico-crítico en el estudio de los evangelios y afirmando ser "solamente un humilde descifrador de textos", relegaba el ámbito filosófico y teológico en su estudio, pues no aceptaba la injerencia ajena al propio método histórico y filológico de su trabajo.

Con ello, la distancia entre historia y fe, entre datos históricos y afirmaciones dogmáticas, parecía inevitable. Cuestiones vivas del momento como la conciencia de Jesús, o el origen de la Iglesia, aparecían en dos estratos separados: en el histórico, no era posible afirmar nada que trascendiera a los "hechos históricos" a los que - a su juicio- se llegaba por medio de la investigación histórica. Al lado de ese Jesús de la historia, la predicación anuncia un Cristo y una Iglesia que son objeto de fe, y lo hace en nombre de factores ajenos a la historia científicamente atestiguada. El resultado, como queda patente, era la separación entre la historia y la fe, entre el conocimiento científico y el contenido de la revelación. Fe y ciencia -en este caso históricaSerían dos niveles que no se comunican (Izquierdo 1999, 924).

La posición de Loisy lo ubicaba en un historicismo para el que solo el método de la ciencia histórica podía hablar con fundamento racional sobre las creencias cristianas y cuyo extremo opuesto era el extrincesismo, que anulaba de hecho la historicidad de la Revelación, sometiéndola de tal manera al carácter eterno de la verdad revelada que no era posible un conocimiento científico de esa historia, considerada insignificante. En estas dos corrientes (historicismo y extrincesismo) existe un dualismo que rompe la relación entre lo natural y lo sobrenatural. 
Sin poder reclamar dominio en los campos de la teología y la ciencia histórica, Blondel no se excluyó de esta discusión, pues sabía que los verdaderos problemas alrededor de este asunto se resolvían a un nivel mucho más profundo que el de las discusiones exegéticas, y en ese nivel, la filosofía de la acción tenía mucho que aportar. "Blondel ha desarrollado en La Acción sobre todo el aspecto de la ciencia, quedando la fe en un plano secundario. Algunos años más tarde se ocupó de las relaciones entre ambas de modo explícito" (Izquierdo 1999, 924).

La obra se compone de tres partes: "El problema"; "Soluciones incompletas e incompatibles" y "El papel vital y el fundamento filosófico de la tradición". Casi dos terceras partes del ensayo están centradas en la crítica y la tercera propone la solución blondeliana al dilema a través de la Tradición. Sin embargo puede decirse que en últimas esta división corresponde a la crítica del extrincesismo (I); a la crítica del historicismo (II) y a la Tradición (III).

Comienza presentando un panorama muy claro de la cuestión a desarrollar. Luego de exponer las doctrinas adversas, Blondel echa mano de principios, expresiones y fórmulas utilizados en las cartas dirigidas a Loisy. Los tópicos principales siguen siendo el método y la cuestión cristológica, a las que se agrega la exposición sobre la Tradición y la práctica fiel del cristianismo que tal vez sean los más originales de Historia y Dogma en relación con la correspondencia antes mencionada, en la que los demás asuntos ya habían sido tratados a profundidad.

Tal vez, el concepto de la voluntad que quiere en esta obra no esté tan presente como en la anterior, sin embargo, no es poca su importancia, considerando que el puente trazado por Blondel entre la inmanencia de los hechos históricos y la dimensión sobrenatural presentada en el dogma se construye con las bases que aporta la filosofía de la acción, en la que sigue siendo clave la expansión de la voluntad.

Por lo anterior, la experiencia del creyente no es un aspecto secundario o de poco interés para el autor, porque en ella se fundamenta la apertura a lo trascendente que pretende mostrar en el Jesús histórico algo más que un personaje revolucionario, un líder carismático o un hombre iluminado con un alto grado de capacidades intelectuales. Blondel no duda en presentarlo como el Mediador entre lo trascendente 
y lo inmanente pues solo por Él "nuestra voluntad puede adecuarse a sí misma” (Blondel 1996, 450). Ya en La Acción se encuentran algunas pinceladas de esta particular cristología filosófica que caracteriza al pensador francés y que se irá completando en obras posteriores:

Para hacer de Dios el fin del hombre según la necesidad imperiosa de nuestra voluntad, para convertirse en su cooperador, para conducir toda vida a su fuente y a su destino, hace falta una ayuda, un intercesor, un pontífice que sea como el acto de nuestros actos, la oración de nuestra oración y la ofrenda de nuestro don (...) Al hombre le es esencial un auxilio no sólo para creer y actuar, para conocer y realizar la verdad, sino sobre todo para remediar las debilidades inevitables de la acción (Blondel 1996, 450).

Aquí se ve bastante bien como Cristo es respuesta concreta a una voluntad que no halla su equilibrio en el mundo y se descubre incapaz de dar por los esfuerzos de la acción con el objeto que quiere. Esta experiencia de inadecuación compartida por los creyentes en distintos momentos históricos y que obtiene respuesta en el Mediador hace parte de lo que Blondel entiende por Tradición y que prolonga en el tiempo los acontecimientos que relata el Evangelio.

La Tradición en su acepción religiosa es mucho más que la transmisión histórica de contenidos y doctrinas. En Historia y Dogma significa una unidad de pensamiento, actos, experiencias y esperanzas entre los hombres de cualquier época o lugar, que siguen encontrando en la acción de un Cristo viviente el llamado a imitar su ejemplo de caridad, entrega y sacrificio, prácticas por medio de las cuales el hombre se conforma con Cristo y teniéndolo en sí mismo puede encontrar la solución a la dialéctica de la voluntad:

Sí o no ¿la acción de Cristo no fue más que un medio para suscitar un movimiento de la conciencia religiosa, y la verdad cristiana es sólo una verdad que sólo actúa si es conocida, que podría limitarse a ser un ideal del que se beneficiarían solo quienes la conocen y en la medida en que toman sus ejemplos de su propio fondo? ¿O bien es una realidad, un 
fin tanto como un medio, que adquiere a través de la Encarnación un papel metafísico, que responde por medio de la Redención a exigencias morales y sustanciales, y se aplica bajo ciertas condiciones incluso a quienes ignoran su eficacia? (Blondel 2004, 157).

Las exigencias morales y sustanciales a las que se refiere Blondel constituyen nada más y nada menos que el deseo natural del fin sobrenatural pues "tampoco al vivir podemos sustraernos a la radical y universal penetración de algo que siempre impedirá al hombre encontrar su equilibrio en el orden humano" (Blondel 2004, 158) y es aquí donde Historia y Dogma hace referencia al estado sobrenatural en el que el hombre es colocado para poder realizar esa vida de gracia a la que está invitado. Si en él existe una dialéctica de la voluntad puede entenderse como "una vocación primera, un estado que resulta de la pérdida del don inicial, pero como una necesidad y una aptitud para recibir su sustitución" (ibídem, 159).

Solo cuando el hombre somete su razón y apuesta por vivir de acuerdo a la Revelación, "sustituyendo con la voluntad divina el amor propio" (Blondel 1996, 494) se une al caudal inmenso de la Tradición y así, por la vivencia del amor se ilumina su intelecto, frágil y limitado para acceder por sí mismo a las profundidades del ser y su voluntad recibe aún más del don que esperaba.

Es posible que las "disposiciones de ánimo" (Blondel 1991, 29) referidas en la Carta Apologética no sean otra cosa que el sacrificio de la inteligencia y de la voluntad, la docilidad práctica que no se detiene ante las contradicciones que se presentan al conocimiento, porque sabe que forman parte de una realidad más amplia que él mismo. El hombre anhela lo infinito, y el único modo de alcanzarlo es abriéndole un espacio en sí mismo por la muerte personal y la renuncia, por eso, así como en la tesis de 1893 el vínculo entre el conocimiento y el ser es la acción, en Historia y Dogma, inmanencia y trascendencia, voluntad humana y creencia, hechos y dogmas encuentran su unidad sintética no en una abstracción racional de las ciencias, sino en la acción fiel de cada hombre: 
"Guardar la palabra de Dios", es en primer lugar, practicarla. Y el depósito de la Tradición, que las infidelidades de la memoria y las estrecheces de la inteligencia deformarían inevitablemente si nos fuera entregado bajo una forma completamente intelectual, sólo puede ser transmitido íntegramente, más aún, sólo puede utilizarse y desarrollarse si es confiado a la obediencia práctica del amor. La acción fiel es el arca de la alianza donde habitan las confidencias de Dios, el tabernáculo en el que él perpetúa su presencia y sus enseñanzas. Si la verdad esencial del catolicismo es la encarnación de las ideas dogmáticas en los hechos históricos, hay que decir recíprocamente que la maravilla de la vida cristiana es que, de los actos al principio quizá dolorosos, oscuros e impuestos, llegamos a la luz por medio de una verificación práctica de las verdades especulativas (Blondel 2004, 146).

Para superar el inmanentismo y el subjetivismo modernos para los cuales todo quedaría reducido al pensamiento y conocimiento del sujeto; para afirmar la metafísica, el ser y la consistencia real de los objetos sin que queden reducidos en el idealismo, hace falta un elemento distinto de la ciencia que es la práctica efectiva, que soluciona para cada uno la cuestión de las relaciones del alma y Dios porque conocer es ser lo que conocemos y no se puede conocer a Dios, no se puede tener dentro a Dios más que obrándolo, viviendo el amor, dedicándose "muy concretamente y desde muy cerca a alguna humilde obra de misericordia" (Blondel 1996, 498). Es en este tipo de "prácticas experimentadas", "luces adquiridas por la piedad", en "la plegaria y la mortificación" (Blondel 2004,146 ) donde no solo se encuentra al ser por la vía del amor sino que la Tradición encuentra su sustento y criterio regulador.

La práctica revela su extraordinaria fecundidad, no sólo en la acción individual, sino también en la solución de problemas análogos a los de ésta en la sociedad creyente. Es el problema de Histoire et Dogme. La "laguna filosófica", de la que habla Blondel, entre los datos históricos y los dogmas es paralela a la irreductibilidad entre inteligencia y fe. La solución (...) la encuentra Blondel en la "práctica colectiva", 
en la "acción fiel" que es el elemento clave de la tradición. Aparecen entonces en Histoire et Dogme términos familiares para el lector de L'Action: "verificación práctica", "vida moral", "obediencia práctica del amor", etc. Todos ellos son elementos que forman parte de la definición integral de tradición que Blondel propone en la tercera parte de Histoire et Dogme, y que tienen su antecedente en la quinta parte de L’Action (Izquierdo 1990, 288).

En el núcleo de esa ciencia de la acción que enlaza la dogmática y la exégesis se encuentra el amor vivido entre todos los hombres y de cada uno hacia Cristo. Pretender estudiar el Evangelio y la Iglesia como quien disecciona cadáveres y negando ilegítimamente de plano todo carácter metafísico en su relación es olvidar, con graves consecuencias para la investigación histórica y teológica que "lo que Jesús buscó y obtuvo, no es ser analizado como un tema teológico, sino ser amado por encima de todo" (Blondel 2004, 112) y que si se intentar reducir a Cristo a la inmanencia, no por ello el grito de la voluntad dejaría de pedir mucho más, dado que en él existe un ineludible bautismo de deseo que solo sacia el infinito.

\section{Conclusión}

Una nota característica de nuestro tiempo es la búsqueda espiritual de hombres y mujeres que encuentran insuficiente una vida en torno al trabajo, la eficiencia profesional y el consumo.

Desde las grandes religiones, pasando por cultos sincréticos hasta diversos tipos de sectas intentan responder a la inquietud del corazón humano, que siempre está buscando algo más allá del horizonte material y subjetivo. Tal panorama de lo que podríamos llamar "oferta espiritual" conduce inevitablemente a un relativismo religioso, y lo que antes parecía ser revelación de lo divino se convierte en respuesta que el hombre crea para sí mismo desde su propia inmanencia, en una especie de "mística de la identidad" (cfr. Ratzinger 2005, 41) que suprime la contraposición entre el Yo humano que busca la trascendencia y el Tú divino que se revela en un lenguaje comprensible para el hombre, pero que le abre 
una dimensión que no está a su alcance por su propio esfuerzo. Desde esta perspectiva, los conceptos que remiten al hombre a lo sobrenatural carecerían de realidad y no serían más que categorías para poetizar la inmanencia, para resignificar un hecho que expresado en los términos concretos de un Feuerbach, un Marx o un Nietzche suena terrible: El hombre está solo en el universo y solo debe arreglárselas.

La filosofía de la acción de Maurice Blondel, coherente con los principios del pensamiento moderno y con un método fenomenológico de gran alcance, aporta -desde el concepto de voluntad que quiereelementos fundamentales para un diálogo entre la filosofía y la teología que no se reduzca a una mística de la identidad, reivindicando la metafísica y la ontología, no como consecuencias de la especulación y el intelectualismo realista, sino como necesidades del ser humano que parecieran haber sobrevivido al racionalismo ilustrado, al positivismo de un mundo tecnológico y al sinsentido que pregona una posmodernidad desengañada por las promesas incumplidas de la modernidad.

\section{Bibliografía}

Arrieta Heras, Begoña. 1993. Filosofía y ética en Maurice Blondel. Bilbao: Universidad de Deústo.

Blondel, Maurice. 1990. Carta sobre las exigencias del pensamiento contemporáneo en materia de apologética y sobre el método de la filosofía en el estudio del problema religioso.Trad. de Juan María Isasi. Bilbao: Universidad de Deusto.

Blondel, Maurice. 1996. La Acción (1893) Ensayo de una crítica de la vida y de una ciencia de la práctica. Trad. de Juan María Isasi y César Izquierdo. Madrid: Biblioteca de Autores Cristianos.

Blondel, Maurice. 2004. Historia y Dogma. Trad. de César Izquierdo. Madrid: Cristiandad.

Cartier, Albert. 1955. Existence et Vérité, philosophie blondélienne de l'action et problematique existentielle. Tolouse Privat.

Izquierdo, César. 1990. Blondel y la crisis modernista. Pamplona: Universidad de Navarra. 
Izquierdo, César. 1999. "Relación de la fe con la ciencia. La aportación de Blondel al estudio de la historia y del dogma”. Scripta Theologica. 31: 921-936.

Lautréamont, conde de. 1988. Obra completa. Trad. de Manuel Álvarez Ortega. Madrid: Akal.

Ortega y Gasset, José. 2007. ¿Qué es Filosofía? Madrid: Espasa.

Pieper, Josef. 1970. Defensa de la Filosofía. Trad. de DIORKI. Barcelona: Herder.

Ratzinger, Joseph. 2005. Fe, verdad y tolerancia. Trad. de Constantino Ruiz-Garrido. Salamanca: Sígueme.

Unamuno, Miguel de. 1996. Epistolario americano. Salamanca: Universidad de Salamanca.

Valdés, Luis Fernando. 2008. De la inmanencia a la trascendencia. La apertura del espíritu a lo sobrenatural en Maurice Blondel y Henri de Lubac. México: Cruz O.

Van der Meer, Pieter. 1954. La gran aventura. Buenos Aires: Carlos Lohlé. 